\title{
Hereditary Pyropoikilocytosis and Elliptocytosis: Clinical, Laboratory, and Ultrastructural Features in Infants and Children
}

\author{
JOSEF T. PRCHAL, ${ }^{(32)}$ ROBERT P. CASTLEBERRY, RICHARD T. PARMLEY, WILLIAM M. CRIST, \\ AND AHMAD MALLUH \\ Divisions of Hematology and Pediatric Hematology, University of Alabama at Birmingham, \\ Birmingham, Alabama, USA
}

\begin{abstract}
Summary
Clinical, biochemical and ultrastructural assessment of five Black children from four unrelated kindreds, who had morphologic and laboratory features of hereditary pyropoikilocytosis (HP) is described. In two of the unrelated propositi, both with relatives having elliptocytosis, the apparent HP gradually evolved into elliptocytosis. The mode of inheritance appeared to be autosomal dominant in one family and autosomal recessive in the other. None of the three children from two separate families with true HP had a parent with HP or elliptocytosis. A sixth Black child, whose mother also had elliptocytosis, demonstrated typical elliptocytosis from birth and never demonstrated the HP phenotype. Sequential quantitation of heat induced red cell fragmentation using histogram analyses revealed unchanged findings in three patients with true HP but progressive amelioration in the two patients with HP phenotype who eventually developed elliptocytic morphology. Previously unreported lesions in both true and apparent HP patients included endovesicle formation and submembrane particles, which were detected by electron microscopy, an increase in Heinz body formation, and elevation of oxidized glutathione levels. Our study demonstrates shared abnormalities present both in some neonates with elliptocytosis and in neonates with $H P$, which preclude the diagnosis of $\mathrm{HP}$ in infancy and provide further evidence of the heterogeneity of the elliptocytosis syndrome.
\end{abstract}

\section{Speculation}

We provide evidence for clinical and genetic heterogeneity of the pyropoikilocytic phenotype. We propose that this heterogeneity may be explained in part by the fact that some patients with pyropoikilocytic elliptocytosis exhibit pyropoikilocytic changes only during infancy and later develop an elliptocytic phenotype perhaps due to the added influence of characteristics unique to neonatal erythrocytes. Furthermore we hypothesize that the oxidative damage found in patients with pyropoikilocytic phenotype may contribute to the hemolytic process of hereditary pyropoikilocytosis.

Hereditary pyropoikilocytosis (HP) is an uncommon congenital hemolytic anemia. Zarkowsky et al. $(28,29)$ proposed this term to describe two patients with congenital hemolytic anemia whose erythrocytes exhibited marked morphologic abnormalities resembling erythrocytes of subjects with severe burns and hemolysis. In addition. these red cells had an in vitro propensity to fragment and form characteristic membrane projections at temperatures between $46-49^{\circ} \mathrm{C}$, as compared to normal red cells which undergo similar changes only at or above temperatures of $49^{\circ} \mathrm{C}$. A similar hemolytic disorder was previously described $(7,15)$. Neither the mode of inheritance nor the molecular defect of HP has been identified; however, several abnormalities including abnormal calcium flux and red cell membrane structure (26), instability and abnormal tertiary structure of spectrin $(6,17)$ and spectrin phosphorylation (25) have been reported.

In comparison, hereditary elliptocytosis (HE) is a widely recognized red cell morphologic abnormality often associated with varying degrees of hemolysis. The mode of inheritance is autosomal dominant (14) and homozygotes are known to have a severe hemolytic process (27). A number of separate defects have been described in individual families indicating that it is likely a heterogeneous disease although these abnormalities do not necessarily constitute a cause and effect relationship.

Recently it has become apparent that HP and HE may be related. For example, some of the described patients with HP have relatives with elliptocytosis. In addition it has been reported that certain infants who eventually develop elliptocytic red cell morphology may have transient morphologic features resembling those of HP $(29,30)$. The purpose of this paper is to report the clinical, genetic, laboratory and ultrastructural findings of six Black children from five unrelated families presenting with HP phenotype or elliptocytosis and to demonstrate the heterogeneity of these disorders.

\section{CASE REPORT}

One female and five male children with abnormal red blood cell morphology were studied. All patients were Black. They were referred to the Children's Hospital in Birmingham at the ages of 2 months- 8 years. The family pedigrees are depicted in Figure 1.

On repeated follow-up assessments subjects $1,2 \mathrm{a}$, and $2 \mathrm{~b}$ maintained stable hemoglobin concentrations (mean $8.5 \mathrm{~g} / \mathrm{d}$; range $5.5-10.3$ ) as well as rates of hemolysis, and their erythrocyte morphology did not change substantially. In contrast, the degree of anemia (mean hemoglobin $9.3 \mathrm{~g} / \mathrm{d}$; range $7.8-12.3$ ) and rate of hemolysis of subjects 3 and 4 have progressively ameliorated. The blood films from early infancy of these two subjects were indistinguishable from subjects $1,2 \mathrm{a}$, and $2 \mathrm{~b}$ (Fig. 2a, blood film from patient 3 at the time of his initial evaluation). Typical elliptocytic morphology, featuring only occasional red cell membrane projections, was noted by the age of 16 months and 13 months respectively (Fig. 2b).

Unlike the above five patients, the patient from family 5 , who was first examined at the age of 2 days, had typical elliptocytic morphology without microspherocytes or significant red cell membrane projections. His mother had similar red cell morphology. Neither the mother nor the patient were anemic or had evidence of hemolysis. This patient had coincidential congenital agranulocytosis.

\section{MATERIALS AND METHODS}

Hematologic studies. The Heinz body preparations, sugar water test, cellulose acetate and agar gel hemoglobin electrophoreses, 
and isopropanol screen for unstable hemoglobin were performed as described by Beutler et al. (2) and Dacie and Lewis (8).

Heat incubation. The assessment of in vitro fragmentation of red cells upon exposure to heat $\left(37-49^{\circ} \mathrm{C}\right.$ in isotonic buffer, $\mathrm{pH} 7.4$ at
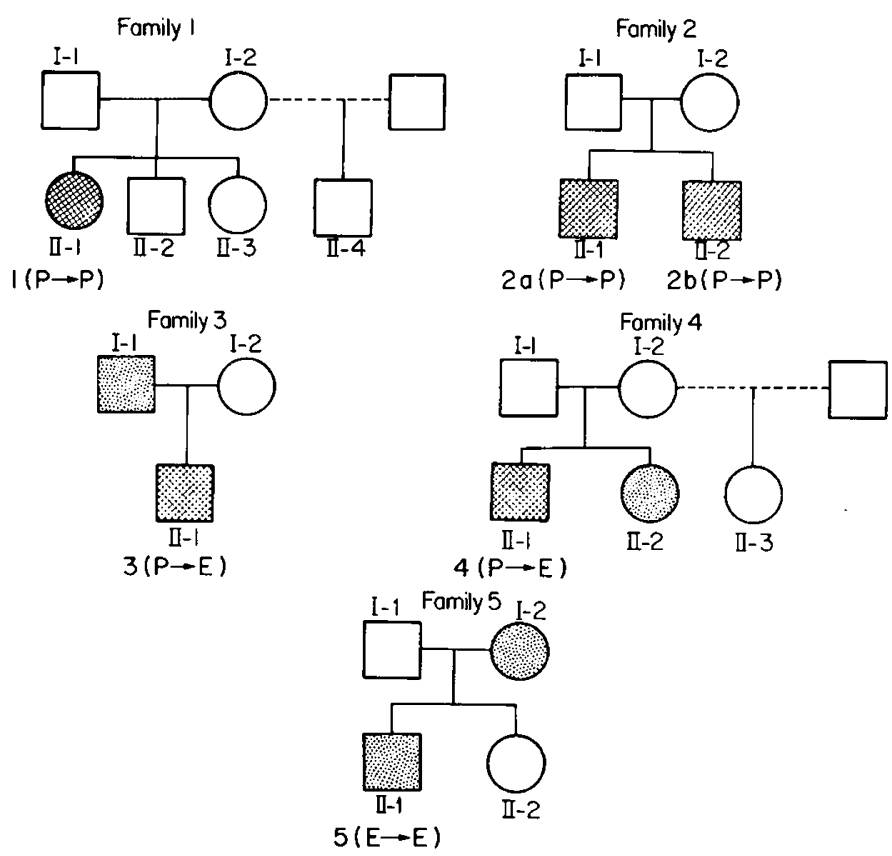

Fig. 1. Pedigree of families 1-5. Cross pattern depicts HP phenotype, solid pattern indicates patients with elliptocytosis. Arabic numerals beneath propositi represent patient number used in text. $(\mathrm{P} \rightarrow \mathrm{P}$, pyropoikilocytosis: $\mathrm{P} \rightarrow \mathrm{E}$, HP phenotype changing to elliptocytic phenotype; and $E \rightarrow E$, elliptocytic phenotype from birth).

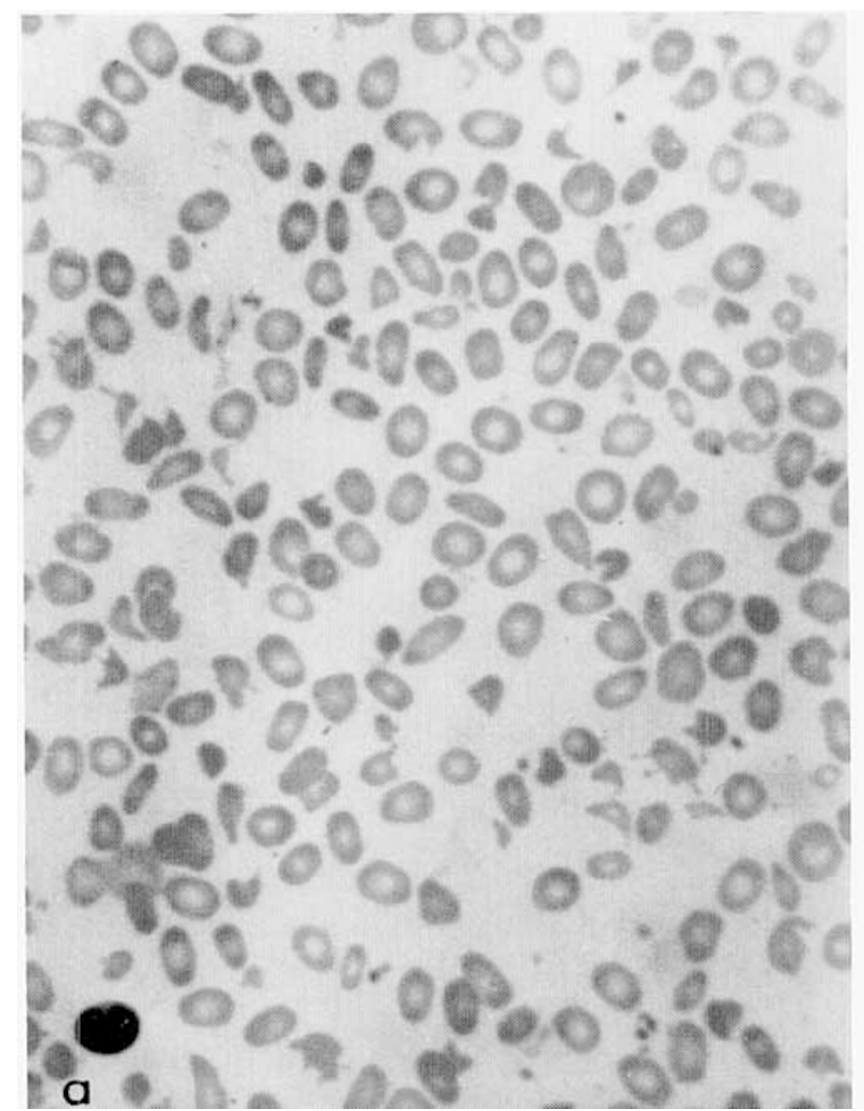

$37^{\circ} \mathrm{C}$ ) was performed as described by Zarkowski et al. (29) and assessed under light microscopy. The technique and instrumentations were identical in early and late experiments and aliquots of the same buffer (kept frozen) were always used. Concommitantly prepared normal red cells as well as buffer-suspended, unincubated erythrocytes of the propositi were examined at the same time

Biochemical studies. In patients $1,2 \mathrm{a}, 3$, and 4, assays of glycolytic and some pentose pathway enzymes (including G-6-PD, 6PGD, glutathione reductase and peroxidase) as well as selected metabolic intermediates reduced glutathione and oxidized glutathione were performed as described by Beutler (3). Normal controls were always concommitantly assayed. Patients $2 \mathrm{~b}$ and 5 were not available for studies.

Histogram analysis. Histogram analysis (20) of red cell fragments was performed using a Coulter-Counter Model S ${ }^{+}$(Coulter Electronics, Hialeah, FL). These histograms graphically evaluated the proportion of particles that ranged in volume from $2-20 \mu \mathrm{m}^{3}$. Previous removal of leukocytes and the majority of platelets by passing through a cellulose column (4) did not materially change the histogram configuration, nor the number of small particles counted.

Electron microscopy. Aliquots of heparinized blood or incubated and unincubated buffer-suspended red cells, were suspended in $3 \%$ glutaraldehyde with $0.1 \mathrm{M}$ cacodylate buffer, $\mathrm{pH} 7.35$, for $1 \mathrm{~h}$ at $4{ }^{\circ} \mathrm{C}$. The cells were centrifuged at $155 \mathrm{Xg}$ for $2 \mathrm{~min}$ and rinsed in $0.1 \mathrm{M}$ cacodylate, $7 \%$ sucrose buffer. For transmission electron microscopy, the cells were postfixed for $1 \mathrm{~h}$ in $1 \% \mathrm{OsO}_{4}$ in $0.1 \mathrm{M}$ cacodylate buffer, routinely dehydrated in graded ethanols and propylene oxide, and embedded in Spurr low viscosity medium. Thin sections $(60 \mathrm{~nm})$ were collected on copper grids and stained with uranyl acetate and lead citrate. Sections were examined in a Philips 300 electron microscope at an accelerating voltage of 60 $\mathrm{kV}$. Cationized ferritin and differential staining with diaminobenzidine were used as previously described $(9,11)$.

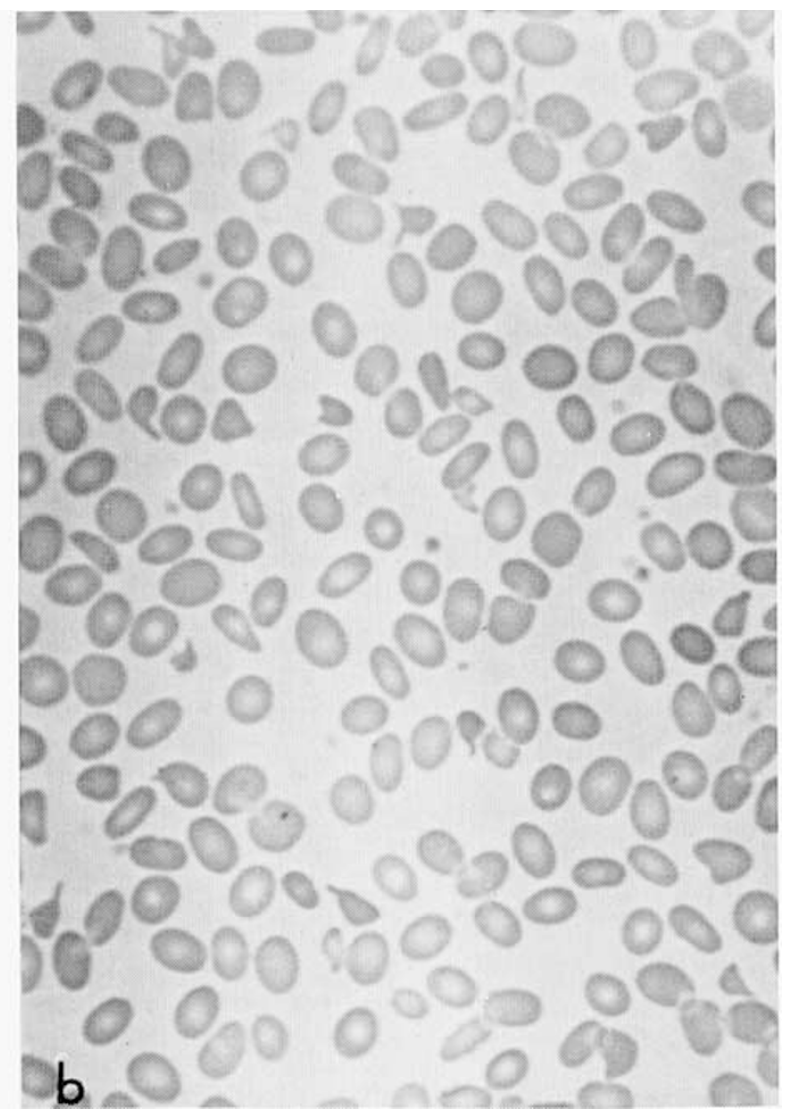

Fig. 2a. (Left hand panel), blood film from patient 3 at the age of 2 months. Numerous membrane projections, microcytes and ovalocytes are noted. Figure 2b, (Right hand panel), blood film of patient 3 at the age of 16 months demonstrating transition to elliptocytic morphology. 
Genetic studies. Various erythrocyte antigens, lymphocyte HLA antigens and selected polymorphic serum genetic markers were assayed by Dr. Wilma Bias at the Immunogenetics Laboratory of the Johns Hopkins University as previously described (10).

\section{RESULTS}

Hematologic studies. With the exception of patient 1 who had hemoglobin CC disease, all other patients had normal hemoglobin electrophoretic patterns in both alkaline and acid media and had appropriate hemoglobin $\mathrm{A}_{2}$ and $\mathrm{F}$ levels for their age. All of the patients had negative isopropanol screen for unstable hemoglobin, sugar water test, and Coomb's test.

Four of the six patients (patients $2 \mathrm{~b}$ and 5 were not studied) demonstrated abnormal Heinz body formation (mean $55 \%$ positive cells, range 36-84\%) when erythrocytes were incubated for $4 \mathrm{~h}$ at $37^{\circ} \mathrm{C}$ with acetylphenylhydrazine. In contrast, significant Heinz body formation was not observed in the relatives with asymptomatic elliptocytosis or normal controls (mean 9\% positive cells; range $8-11 \%$ ).

Genetic studies. All members of Families 2, 3 and 4 agreed to undergo genetic studies to confirm paternity. The odds favoring paternity in Families 2 and 3 were 97:1 and 1766:1, respectively.

For Family 4, the father was excluded from paternity of one of the daughters (II-3). Odds favoring his paternity of II-1 (patient 4) and II-2 were 51.33:1 and 96.25:1, respectively.

Heat incubation. The erythrocytes from all patients and relatives, with the exception of the father of patient 1 and patient 5, were examined. On repeated testing, erythrocytes from patients 1-4 consistently demonstrated marked fragmentation and membrane projections after heat exposure. Concommitantly processed samples from three patients with hemoglobin SS disease, two patients with hereditary spherocytosis, and one patient each with hemoglobins CC, AC and SC exhibited none of these characteristic morphologic changes. In addition, the two relatives with asymptomatic elliptocytosis, the father of patient 3 and the sister of patient 4 , also had positive heat incubation tests although the morphologic abnormalities were not as marked as those present in blood samples from their anemic relatives.

Although there was complete agreement about frankly positive or negative tests among five hematologists, the attempted grading of abnormalities varied significantly among interpreters. This is perhaps due to the inferior erythrocytic and morphologic details, which are inherent to erythrocytes suspended in buffer as opposed to plasma, despite the addition of albumin to the sample. To eliminate the subjectivity of interpretation and to facilitate quantitation of the degree of fragmentation, histograms were performed. Figure 3 a records the results from the propositus of Family 4, his sister with elliptocytosis and a normal control. In addition to the expected increased number of fragments observed in the patient, his sister with elliptocytosis demonstrated lesser but still abnormally high numbers of fragments compared to controls. Similar results were obtained from the propositi of Families 1-3 and the father of Family 3 who had elliptocytosis. In contrast, a concommitantly tested healthy 2 -day-old neonate had a significant proportion of fragments only at $48^{\circ} \mathrm{C}$ (Fig. 3b).

Biochemical studies. With the exception of elevated activities of erythrocyte age dependent enzymes, most notably of hexokinase and G-6-PD, no other abnormalities of enzymes in the glycolytic and pentose pathways were detected. All patients studied also had normal levels of glutathione reductase.

Erythrocyte reduced glutathione (GSH) and oxidized glutathione (GSSG) levels are shown in Table 1. Although the GSH levels of subjects with apparent pyropoikilocytosis and those relatives with $\mathrm{HE}$ were normal, erythrocyte GSSG levels were increased in patients $2 \mathrm{a}, 3$, and 4 . Patient 1 with HP and concommitant $\mathrm{Hb} \mathrm{CC}$ had on one occasion an elevated erythrocyte GSSG but on two repeated testings her GSSG levels were within normal limits. The possibility that patient I was heterozygous for G-6-PD deficiency was ruled out by G-6-PD electrophoresis, which re-
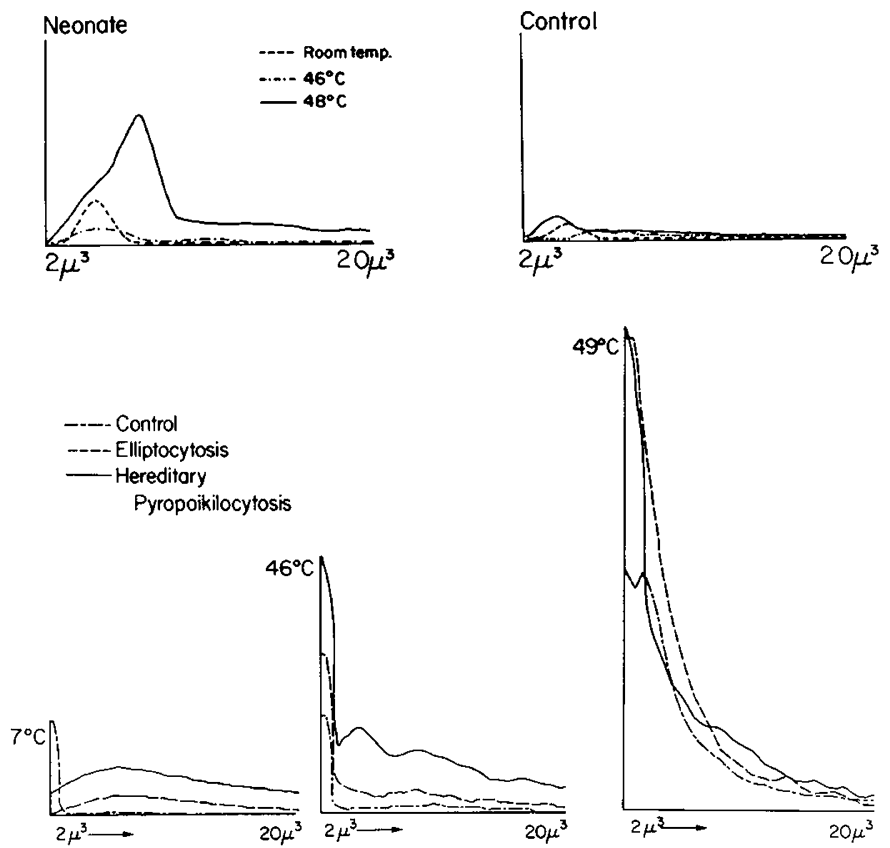

Fig. 3a. (Lower panel), relative numbers of red cell fragments ranging between $2-20 \mu \mathrm{m}^{3}$ in volume at $37^{\circ} \mathrm{C}, 46^{\circ} \mathrm{C}$, and $49^{\circ} \mathrm{C}$ from patient 4 , his sister with elliptocytosis, and a normal control are depicted. Figure $3 \mathrm{~b}$, (Upper panel), histogram analysis of a normal neonate and an adult control.

Table 1. Reduced glutathione (GSH) and oxidized glutathione (GSSG) GS levels in four subjects with pyropoikilocytic phenotype and in their two relatives with elliptocytosis. Father of patient 3 with elliptocytosis is abbreviated EL-3. Sister of patient 4 with elliptocytosis is abbreviated EL-4. Open bars denote patient's level of GSSG, solid bars indicate erythrocyte GSSG level of concommitantly tested controls. (NA = not applicable. Normal range expressed as mean $\pm S . D$.

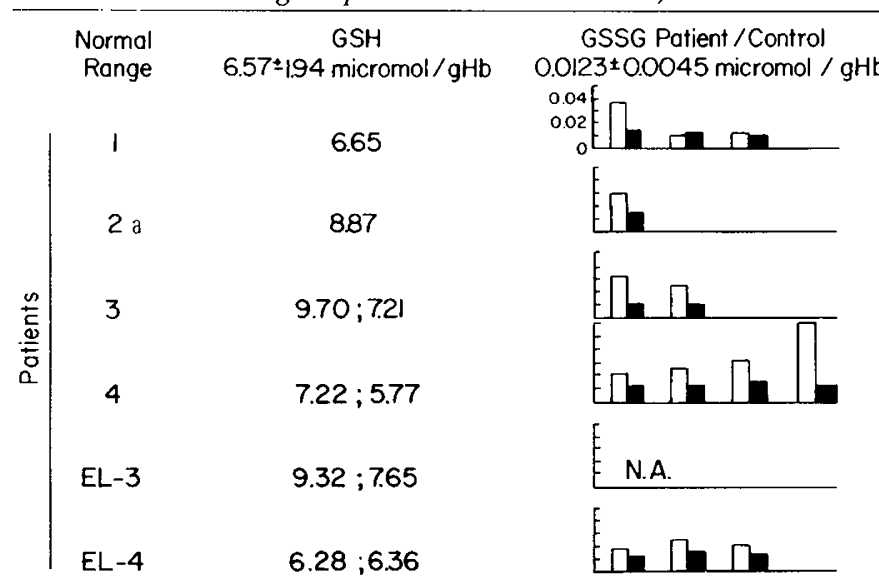

vealed presence of G-6-PD B isoenzyme only. Erythrocyte GSSG was also measured in the sister of patient 4 who had elliptocytosis. Minimal but definite increase of her erythrocyte GSSG was also demonstrated.

Electron microscopy studies. Transmission electron microscopy revealed typical morphologic changes of $\mathrm{HP}$ erythrocytes following incubation at $46^{\circ} \mathrm{C}$, which are illustrated in Figure $4 \mathrm{a}$. With increasing temperature, there was marked herniation of the red cell membrane, erythrocyte fragmentation and the appearance of increased numbers of small particles. These findings concur with the histogram results described above. In addition, prominent endovesicle formation occurred, being more evident in the patient from Family 1 than in the propositi of Families 2-4. Patient 4 had 

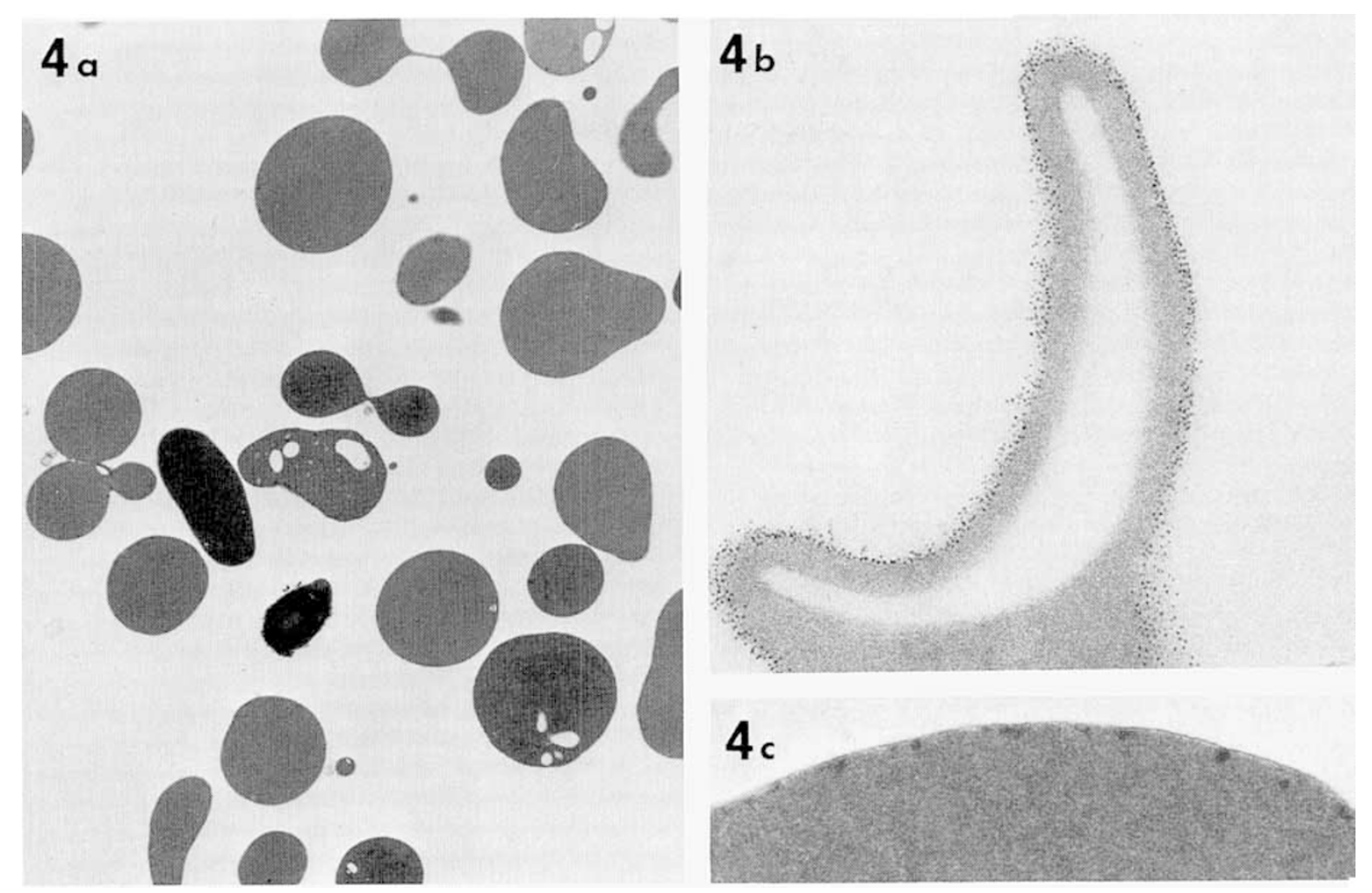

Fig. 4a. Transmission electron micrograph of erythrocytes from patient $2 \mathrm{a}$ incubated at $46^{\circ} \mathrm{C}$. Note the appearance of endovesicles, increased fragmentation, and submembrane particles $(\times 3300)$. Figure $4 b$, The absence of staining of anionic glycoconjugates with cationized ferritin in the endovesicle membrane compared to the plasmalemma suggests a lack of continuity of these areas $(\times 72,000)$. Figure $4 \mathrm{c}$, Submembrane particles are depicted with uranyl acetate/lead citrate. The inability to visualize these particles on an unstained preparation confirms the lack of innate electron density and osmiophilia $(\times 20,000)$.

the least endovesicle formation. The lack of continuity of the endovesicles with the plasmalemma was established by the failure of cationized ferritin to stain anionic glycoconjugates in the endovesicle membrane (Fig. 4b).

Simultaneous with the vacuolization of the erythrocytes after heating was the appearance of discrete $50-100 \mathrm{~nm}$ submembrane precipitates that seem to be adherent to the inner surface of the red cell membrane. These were clearly observed after staining with uranyl acetate and lead citrate (Fig. 4c) but could not be seen in unstained preparations and therefore lacked innate electron density and osmiophilia. Some of these particles stained heavily with diaminobenzidine, demonstrating hemelike activity. These structures appeared after incubation at $45^{\circ} \mathrm{C}$ in more than $90 \%$ of the erythrocytes from patients $2 \mathrm{a}, 3$ and 4 , but were not observed at any temperature in red cells from HP patient 1 who was homozygous for hemoglobin $\mathrm{C}$.

Those individuals who were at first considered to have hereditary pyropoikilocytosis but proceeded to develop clinical and peripheral blood pictures compatible with elliptocytosis (patients 3 and 4), initially demonstrated ultrastructural changes identical to those described for HP erythrocytes. On subsequent studies, findings from these patients were similar to those observed in their relatives with elliptocytosis. When red cells from the relatives with elliptocytosis were also examined after incubation at $37^{\circ} \mathrm{C}$ and $46^{\circ} \mathrm{C}$, similar though less severe membrane alterations occurred but without significant endovesicle formation. In contrast, patient 5 , who had typical elliptocytosis at birth, demonstrated no endovesicles, submembrane particles or membrane projections in an unincubated specimen. Erythrocytes from a 2-day-old normal neonate failed to exhibit submembrane particles whereas heatinduced endovesicle formation was seen, though less than that seen in HP erythrocytes. Similar changes in morphology did not occur in normal erythrocytes or in those from patients with hemoglobin $\mathrm{C}$ or hereditary spherocytosis until heating to $49^{\circ} \mathrm{C}$.
It is interesting that all the aforementioned abnormalities occurred in both erythrocytes and reticulocytes but were far more pronounced in the latter. This might indicate an increased susceptibility to heat-induced damage and thus increased fragility of this population of erythrocytes and would provide an explanation for the observed decreasing \% of reticulocytes with increasing temperature (Fig. 5)

\section{DISCUSSION}

This report describes five patients from four separate kindreds who had the phenotype of pyropoikilocytosis during infancy. Diagnosis of these patients was entirely based on conventional criteria, which included light microscopic morphology and heatinduced fragmentation. We have demonstrated that this abnormality can be quantitatively assessed by using a histogram analysis of red cell fragments and have described additional lesions that include endovesicle formation, presence of submembrane particles and glutathione abnormalities. Two of these patients eventually developed elliptocytosis, which became evident by 1 year of age. Coincidentally, heat-induced fragmentation and endovesicle formation decreased as elliptocytic features appeared, whereas submembrane particles and glutathione abnormalities persisted. These findings demonstrate shared abnormalities in patients with pyropoikilocytosis and some patients with elliptocytosis, which preclude the diagnosis of hereditary pyropoikilocytosis in infancy.

To our knowledge all reported patients as well as our four families with HP phenotype were Black. Due to the small sizes of families, conclusions about a mode of inheritance of HP and of HP phenotype are necessarily limited; however, the genetic inheritance pattern of true HP appeared consistent with an autosomal recessive mode in both families studied. A new mutation cannot be excluded in Family I or X-linked inheritance in Family 2. One of our patients, 4 , with HP phenotype in infancy who eventually 
developed $\mathrm{HE}$, demonstrated an autosomal recessive mode of inheritance based on the findings of the abnormality in his sister and not in his parents. This is similar to the New Guinea variant of elliptocytosis, which is also inherited in the autosomal recessive mode as described by Booth, et al. (5) and Amato (1). In contrast, two of the patients with $\mathrm{HE}$, one with pyropoikilocytic phenotype in infancy (patient 3) and one with the elliptocytic morphology since birth (patient 5), demonstrated an autosomal dominant mode of inheritance. This clinical, morphologic and genetic heterogeneity of our patients is summarized in Table 2.

The formation of heat-induced endovesicles has not been previously reported in pyropoikilocytosis. It represents another manifestation of membrane instability in these cells. Walter et al. (25) have noted that pyropoikilocytic red cells may form more druginduced endovesicles than control erythrocytes. Endovesicle formation may be related to the previously reported abnormalities of red cell membrane spectrin in this disorder; however it has been reported by Schrier, et al. (22), Greenwalt et al. (12) and Hardy et al. (13) that the endovesicle formation can be induced in erythrocytes with normal spectrin by a number of pharmacologic agents.

The presence of submembrane particles detected by transmission electron microscopy in three out of four subjects with apparent HP is another previously unrecognized finding. Their differential staining with benzidine and our finding of positive Heinz body tests in these patients further suggest that these particles are precipitated hemoglobin; however, we were unable to detect Heinz
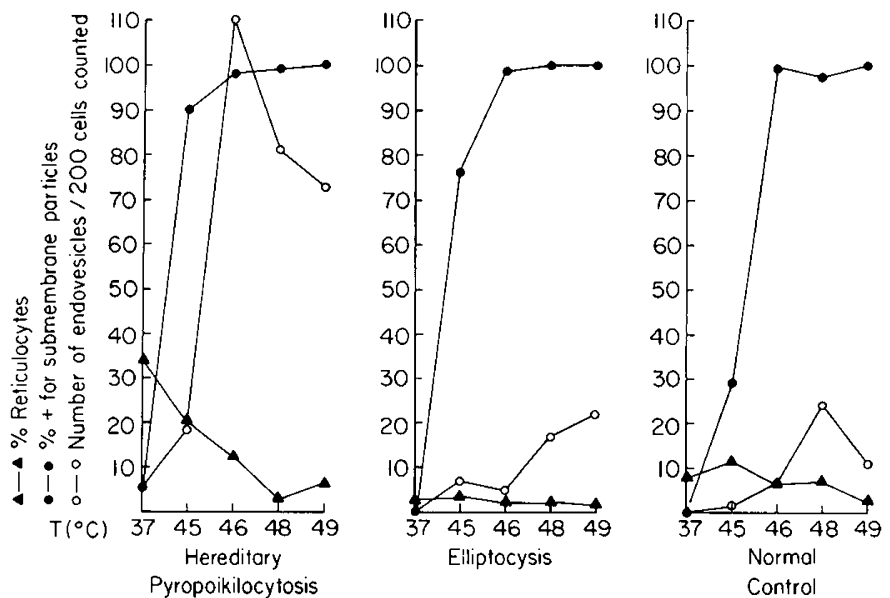

Fig. 5. Comparison of heat-induced ultrastructural changes (number of endovesicles, \% of cells containing submembrane particles and proportion of reticulocytes) in patient 4 , his sister and a normal control. Patient 4 demonstrates HP phenotype (similar changes found in true $\mathrm{Hp}$-not illustrated), his sister represents an example of elliptocytosis. Reticulocytes were defined as cells containing polyribosomes and/or mitochondria. bodies without incubation with an oxidant (acetylphenylhydrazine), suggesting that the observed hemoglobin instability is relatively subtle. The conditions usually associated with this finding such as an unstable hemoglobin molecule, acute exposure to oxidants or abnormalities of glutathione metabolism, have been ruled out. At least three out of four subjects with apparent HP had elevated erythrocyte GSSG. The elevation of GSSG would result in a decreased GSH/GSSG ratio that could conceivably lead to hemoglobin precipitation. The nature of the elevated erythrocyte GSSG observed in our patients is not obvious. Impairment of active unidirectional GSSG transport, which has been described by Srivastava and Beutler (23), Prchal et al. (19) and Lunn et al. (16), remains an intriguing possibility. The recent demonstration of Palek et al. (18) (based on studies of patients 1 and 2 described here) of an altered spectrin assembly in HP, which was not present in a subject who had G-6-PD deficiency and chronic hemolysis, is more in keeping with the premise that a membrane lesion may be the primary defect in HP. Whether the putative abnormality of HP is secondary to defects of the red cell membrane or from oxidative damage mediated by the elevation of GSSG, remains to be elucidated.

We believe that the technique of histogram analysis is a more objective method of evaluating cell fragmentation than subjectively perusing a blood film. Furthermore, the morphologic abnormalities can be quantitated making possible sequential assessment of patients. The gradual decrease of the erythrocyte heatinduced fragmentation of patients who eventually developed elliptocytosis was the earliest discriminating difference that allowed for the separation of patients with true HP from those who later developed HE. Additionally, both our patients as well as those of Zarkowsky (30) who had the HP phenotype evolving into elliptocytosis in later life, appeared to have milder reticulocytosis and anemia.

This prospective study demonstrates that some children who have apparent HP in infancy eventually develop elliptocytosis. It is unclear how many of the previously reported subjects with HP eventually developed elliptocytosis. As previously described by Zarkowsky (30), erythrocytes from a normal term infant studied here demonstrated a propensity to fragment when heat stressed. The degree of this fragmentation was quantitatively less than observed in our four patients but still more than that observed in adult controls (Fig. 3b). Moreover the optimal temperature required for a significant increase of red cell fragmentation was higher $\left(48^{\circ} \mathrm{C}\right)$ than that necessary to induce a similar increase in our patients with HP phenotype $\left(46^{\circ} \mathrm{C}\right)$. It is possible that the interaction of the genetic abnormality in elliptocytosis with the heat fragmentation propensity of the infant erythrocyte membrane and other previously reported peculiarities of the infant red cell membrane, as described by Schekman and Singer (2I) and Tokuyasu et al. (24), leads to a clinical and morphologic picture of HP that eventually reverts to typical elliptocytosis. Such an association however was not found in the infant from Family 5 (Table 2).

Table 2. Summary of disease spectrum of elliptocytosis and pyropoikilocytosis based on the clinical and laboratory investigations of five described families. AR, autosomal recessive; $A D$, autosomal dominant; $P \rightarrow P$, hereditary pyropoikilocytosis; $E \rightarrow E$, hereditary elliptocytosis; $P \rightarrow E$, pyropoikilocytic phenotype changing to elliptocytic phenotype; and ND, not determined.

\begin{tabular}{|c|c|c|c|c|c|c|c|}
\hline \multirow[t]{2}{*}{$\begin{array}{l}\text { Patient } \\
\text { number }\end{array}$} & \multirow[t]{2}{*}{$\begin{array}{l}\text { Apparent } \\
\text { inheritance }\end{array}$} & \multirow[t]{2}{*}{ Clinical symptoms } & \multicolumn{2}{|c|}{$\begin{array}{c}\mathrm{RBC} \\
\text { fragmentation }\end{array}$} & \multicolumn{2}{|c|}{$\begin{array}{l}\text { Endovesicle } \\
\text { formation }\end{array}$} & \multirow{2}{*}{$\begin{array}{c}\begin{array}{c}\text { Submembrane } \\
\text { particles }\end{array} \\
46^{\circ} \mathrm{C}\end{array}$} \\
\hline & & & $37^{\circ} \mathrm{C}$ & $46^{\circ} \mathrm{C}$ & $37^{\circ} \mathrm{C}$ & $46^{\circ} \mathrm{C}$ & \\
\hline $\mathrm{l}(\mathrm{P} \rightarrow \mathrm{P})$ & $\mathrm{AR}$ & Severe hemolysis & $3+$ & $4+$ & $2+$ & $4+$ & $0-1+$ \\
\hline $2 \mathrm{a}(\mathrm{P} \rightarrow \mathrm{P})$ & $\mathrm{AR}$ & Severe hemolysis & $3+$ & $4+$ & $\mathrm{I}+$ & $2+$ & $4+$ \\
\hline $2 \mathrm{~b}(\mathrm{P} \rightarrow \mathrm{P})$ & AR & Severe hemolysis & ND & ND & ND & ND & ND \\
\hline $5(E \rightarrow E)$ & $\mathrm{AD}$ & None & 0 & ND & 0 & ND & ND \\
\hline $3(P \rightarrow E)$ & $\mathrm{AD}$ & $\begin{array}{l}\text { Severe hemolysis progressing to mild } \\
\text { hemolysis }\end{array}$ & $\begin{array}{c}3+ \\
0\end{array}$ & $\begin{array}{c}4+ \\
1-2+\end{array}$ & $\begin{array}{l}0 \\
0\end{array}$ & $\begin{array}{l}1+ \\
1+\end{array}$ & $\begin{array}{l}4+ \\
4+\end{array}$ \\
\hline $4(P \rightarrow E)$ & $\mathrm{AR}$ & $\begin{array}{l}\text { Severe hemolysis progressing to mild } \\
\text { hemolysis }\end{array}$ & $\begin{array}{c}3+ \\
0\end{array}$ & $\begin{array}{c}4+ \\
1-2+\end{array}$ & $\begin{array}{c}1-2+ \\
0\end{array}$ & $\begin{array}{l}3-4+ \\
0-1+\end{array}$ & $\begin{array}{l}4+ \\
4+\end{array}$ \\
\hline
\end{tabular}


Alternatively, the interaction of a gene for HP and a recessive or dominant gene for $\mathrm{HE}$ (double heterozygosity), along with the above alluded to properties of the infant red cell membrane may lead to apparent HP in infancy.

\section{REFERENCES AND NOTES}

1. Amato, D.: Hereditary ovalocytosis in Melanesians. Papua N. Guinea Med. J., 20: 26 (1977).

2. Beutler. E., Dern, R. J.. Flanagan, C. L.. and Alving. A. S.: The hemolytic effect of primaquine. VIl. Biochemical studies of drug-sensitive erythrocytes. J. of Lab. Clin. Med. 45: 286 (1955).

3. Beutler. E.: Red Cell Metabolism: A Manual of Biochemical Methods. 2nd Ed. pp. 66-73 and 112-117 (Grune \& Stratton. New York. 1975).

4. Beutler, E.. West. C.. and Blume, K. G.: The removal of leukocytes and platelets from whole blood. J. of Lab. Clin. Med., 88: 328 (1976).

5. Booth. P. B.. Serjeantston. S.. Woodfield, D. G.. and Amato, D.: Selective depression of blood group antigens associated with hereditary ovalocytosis among Melanesians. Vox Sanguinis, 32: 99 (1977).

6. Chang. K.. Williamson, J.. and Zarkowsky, H.: Altered circular dichroism of spectrin in hereditary pyropoikilocytosis. Blood (Abstract), 52: 95 (Suppl 1.) (1978).

7. Dacie, J. V.: The Haemolytic Anaemias; Congenital and Acquired. 2nd Ed. Part I. The Congenital Anaemias, p. 151. (Churchill. London, 1960).

8. Dacie, J. V. and Lewis. S. M.: Practical Haematology. 5th Ed.. (Churchill, London. 1975).

9. Danon D.. Goldstein L.. Marvkovsky, Y.. and Skutelsky. E.: Use of cationized ferritin as a label of negative charges on cell surfaces. J. of Ultrastructural Res.. 38: 500 (1972).

10. Donahue, R. P., Bias, W. B., Renwick. J. H., and McKusick, V. A.: Probable assignment of the Duffy blood group locus to chromosome 1 in man. Proc. Natl. Acad of Sci., USA. 61: 949 (1968).

11. Graham. R. C.. Jr. and Karnovsky, M. J.: The early stages of absorption of injected horseradish peroxidase in the proximal tubules of mouse kidney: Ultrastructural cytochemistry by a new technique. J. of Histochem. \& Cytochem., 14:291 (1966).

12. Greenwalt, T. J., Lau, F. O., Swierk, E. M.. and Williams, R. E.: Studies of erythrocyte membrane loss produced by amphipathic drugs and in vitro storage. Br. J. Haematol. 39: 551 (1978).

13. Hardy, B., Bensch. K. G.. and Schrier. S. L.: Spectrin rearrangement early in erythrocyte ghost endocytosis. J. of Cell. Biol.. 82: 654 (1979).

14. Hunter, W. C. and Adans, R. B.: Hematologic study of three generations of a white family showing elliptical erythrocytes. Ann. Intern. Med., 2: 1162 (1929).

15. Lipton, E. L.: Elliptocytosis with hemolytic anemia: the effects of splenectomy. Pediatrics, 15: 67 (1955).

16. Lunn, G.. Dale. G. L., and Beutler. E.: Transport accounts for glutathione turnover in human erythrocytes. Blood, 54: 238 (1979).

17. Palek, J.. Liu. P. A.. Liu. S. C.. Prchal, J. T.. and Castleberry, R. P.: Thermal instability of spectrin in hereditary pyropoikilocytosis. Clinical Research (Abstract), 27: 303A (1979).

18. Palek, J.. Liu, S. C., Liu, P. Y.. Prchal, J., and Castleberry, R. P.: Altered assembly of spectrin in red cell membranes in hereditary pyropoikilocytosis. Blood. 57: 130 (1981)

19. Prchal, J., Srivastava, S. K.. and Beutler, E.: Active transport of GSSG from reconstituted erythrocyte ghosts. Blood, 46: 111 (1975).

20. Prchal. J. T.. Carroll. A. J., Prchal, J. F.. Crist. W. M., Skalka, H. W., Gealy, W. J., Harley, J., and Malluh, A : Wiskott-Aldrich syndrome: cellular impairments and their implication for carrier detection. Blood, 56: 1048 (1980).

21. Schekman. R. and Singer, S. J.: Clustering and endocytosis of membrane receptors can be induced in mature erythrocytes of neonatal but not adult humans. Proc. of the Natl. Acad. Sci., USA. 73: 4075 (1976).

22. Schrier. S. L., Junga, I., and Seeger, M.: The mechanism of drug-induced erythrocyte vacuole formation. J. of Lab. Clin. Med., 83: 215 (1974).

23. Srivastava, S. K. and Beutler, E.: Permeability of normal and glucose-6-phosphate dehydrogenase deficient erythrocytes to glutathione. Biochem \& Biophys. Res. Communication, 28: 659 (1967).

24. Tokuyasu, K. T.. Schekman. R.. and Singer, S. J.: Domains of receptor mobility and endocytosis in the membranes of neonatal human erythrocytes and reticulocytes are deficient in spectrin. J. of Cell. Biol., 80: 481 (1979).

25. Walter. T., Mentzer, W.. Greenquist. A.. Schrier. S., and Mohandas, N.: RBC membrane abnormalities in hereditary pyropoikilocytosis. Blood. (Abstract) 50 (Suppl 1): 98 (1977).

26. Wiley, J. S. and Gill, F. M.: A new form of congenital hemolytic anemia with extreme microcytosis and calcium leak. Pediatr. Res.. (Abstract, 8: 411 (1974).

27. Wyandt, H., Bancroft, P. M., and Winship, T. O.: Elliptic erythrocytes in man. Arch. Intern. Med.. 68: 1043 (1941).

28. Zarkowsky, H. S.. Mohandas, N., Speaker, C. B.. and Shohet. S. B.: Congenital hemolytic anemia due to thermal sensitivity of the erythrocyte membrane. Blood, (Abstract) 42: I (1973).

29. Zarkowsky, H. S., Mohandas. N.. Speaker, C. B., and Shohet, S. B.: A congenital haemolytic anaemia with thermal sensitivity of the erythrocyte membrane. $\mathrm{Br}$. J. Haematol., 29: 537 (1975).

30. Zarkowsky, H. S.: Heat-induced erythrocyte fragmentation in neonatal elliptocytosis. Br. J. Haematol., 41: 515 (1979).

31. Presented in part at the 23rd Annual Meeting of the American Society of Hematology, Phoenix, AZ, December 1979.

32. Requests for reprints should be addressed to: Dr. Josef T. Prchal. Division of Hematology, University of Alabama in Birmingham, University Station. Birmingham, AL 35294.

33. This research was supported in part by grants EY02432 and DE02670 from the National Institute of Health. Dr. Castleberry is a recipient of a Junior Faculty Fellowship of the American Cancer Society.

34. Received for publication July 9. 1981 .

35. Accepted for publication December 3. 1981 